\title{
Três Contribuições Conceituais Neofuncionalistas à Teoria Institucional em Organizações ${ }^{(1)}$
}

\author{
João Marcelo Crubellate
}

\section{RESUMO}

Os esforços mais recentes na teoria institucional em organizações buscam a superação de dicotomias tradicionais quanto a níveis de análise, quanto à relação entre estruturas e capacidade de agência enquanto fontes das práticas sociais e outras. Se em outras áreas da teoria social os esforços de superação destas dicotomias já contam com avanços significativos, em teoria das organizações tais tentativas são muito mais recentes e vêm sendo feitas, na sua maioria, por apropriação de conceitos e teorias de outras áreas, principalmente da Sociologia. Neste sentido o objetivo principal deste ensaio teórico é descrever os conceitos de abertura e fechamento sistêmicos, dupla contingência e expectativa de expectativas - conceitos próprios da teoria dos sistemas sociais autopoiéticos, na perspectiva desenvolvida por Niklas Luhmann - e analisar as possibilidades evidenciadas por tais conceitos para novos encaminhamentos em relação a embates teóricos que há pelo menos duas décadas são travados no âmbito da teoria institucional em organizações.

Palavras-chave: teoria institucional; Luhmann; neofuncionalismo; organizações.

\begin{abstract}
The most recent efforts in institutional theory applied to organization studies search for ways to overcome consequences of traditional dichotomies based on levels of analysis, social structures versus agency as source of practices, and so on. If in other social sciences that debate has received fundamental contributions in the last three or four decades, that is not the case for Organization Theory, where discussions are much more recent and based specially on Sociology authors. The main purpose of this theoretical essay is to describe some neofunctionalist concepts - system openness and closeness, double contingency and expectation of expectations - proposed by Niklas Luhmann, discussing their impact on those dichotomies, in the realm of Luhmannian theory of institutions. This effort is expected to contribute with alternatives to that theoretical discussion that mark institutional organization theory at least in the last two decades.
\end{abstract}

Key words: institutional theory; Luhmann; neofunctionalism; organizations. 


\section{INTRODUÇÃO}

A relação entre organizações e instituições está na raiz dos estudos organizacionais. Isto indica um importante conflito básico como marco das discussões em torno do fenômeno das organizações, qual seja, a discussão a respeito dos fundamentos da ação social, sendo as explicações racionalistas e contingencialistas as alternativas predominantes. Neste sentido a Teoria das Organizações parece caracterizar-se, desde seus primórdios, pela contraposição ao racionalismo das teorias econômicas a respeito do comportamento humano, como evidenciam os estudos de Simon (1970) e Selznick (1957, 1966). Neste sentido a teoria institucional em organizações sempre se mostrou alternativa promissora.

Para Scott (2001) mesmo a perspectiva institucionalista na Economia surgiu oposição ao pensamento baseado no pressuposto de comportamento econômico racional e individualizado. Já no âmbito da Sociologia, duas perspectivas clássicas no tratamento do fenômeno institucional vêm marcar a evolução das discussões em torno daquele tema e afetam, ainda hoje, a teoria organizacional. Essas perspectivas são: a noção funcionalista de determinação ambiental, a partir da qual as instituições eram definidas como fatos sociais em relação aos quais autonomia e vontade própria eram seriamente afetadas; e a noção interpretativista que, não negando a importância de condicionantes sociais, resguardava espaço para a autonomia no âmbito do processo de significação, elemento necessário de toda ação. O desenvolvimento posterior da análise institucional passou a ser norteado por algumas oposições e dicotomias e essas, em decorrência, foram trazidas também para o âmbito da análise organizacional.

Mais recentemente, os esforços na teoria institucional em organizações caminham no sentido de busca de superação de dicotomias tradicionais nas teorias social e organizacional, dicotomias quanto a níveis de análise ou quanto à relação entre estruturas e ação como fontes das práticas sociais. No âmbito da teoria social, já faz algum tempo que se vêm construindo perspectivas de análise da realidade social que apontam caminhos de superação daquelas dicotomias. $\mathrm{Na}$ teoria das organizações, tais tentativas são muito mais recentes e vêm sendo feitas, na sua maioria, por apropriação de conceitos e teorias de outras áreas, principalmente da Sociologia.

Neste artigo propõe-se descrever alguns conceitos da teoria dos sistemas sociais autopoiéticos, na vertente desenvolvida por Niklas Luhmann e, com base em tais 
conceitos, analisar possibilidades alternativas para a teoria institucional em organizações, no que se refere a alguns dos embates teóricos que há pelo menos duas décadas ocorrem no âmbito daquela perspectiva. Para Luhmann a questão da institucionalização se evidencia como central para a explicação dos processos de conformação da realidade social e organizacional. Mas ao contrário de outros autores que também admitem tal centralidade, Luhmann permanece pouco explorado no âmbito da teoria organizacional. Pretende-se aqui contribuir para preencher essa lacuna e, além disso, chamar a atenção para o potencial da perspectiva denominada neofuncionalista na análise de temas organizacionais e administrativos, perspectiva que pode vir a adquirir maior relevância, na medida em que a contemporânea 'sociedade de organizações's se torna cada vez mais complexa.

\section{Indefinições e Conflitos na Teoria Organizacional INSTITUCIONALISTA}

Uma abordagem puramente racionalista da ação é baseada principalmente no pressuposto de que toda ação segue uma lógica de maximização do interesse próprio (Boudon, 1998). Tal noção, como destaca Granovetter (1985, p. 483), é central à Economia Clássica e Neoclássica, sendo fundamentada em "[...] concepção atomizada, subsocializada de ação humana”. Deste modo ação é entendida como produto de sujeitos em busca da maximização de seus próprios interesses, "[...] afetados minimamente pelas relações sociais" (Granovetter, 1985, p. 481). A forma mais radical desta perspectiva admite que o contexto ambiental que cerca os atores sociais (indivíduos ou organizações) é produto da competição entre aqueles atores e, então, a circunstância de atomização social é entendida como premissa lógica para a concorrência perfeita.

Em paralelo a tal versão, desenvolveu-se na Sociologia "[...] uma concepção de pessoas como predominantemente sensíveis às opiniões de outras pessoas e obedientes aos ditames de sistemas de normas e valores consensualmente desenvolvidos, internalizados por meio de socialização [...]" (Granovetter, 1985, p. 483). Essa concepção normativista de ação social, formulada por Parsons (1951), foi tão importante para as teorias social e organizacional quanto recebeu variadas e diferentes críticas. Sua influência é evidente desde os primórdios da teoria das organizações e até hoje, mesmo que não se tenha repetido o mesmo extremismo da concepção normativista de ação. Em teoria das organizações a questão parece ter ficado em termos da tendência de se enfatizar aspectos externos às organizações - dentre eles as instituições - como variáveis independentes em relação aos sistemas sociais, principalmente com a ascensão da noção de sistemas abertos como paradigma analítico. 
Nessa perspectiva, a década de 70 vai-se constituir em marco na teoria organizacional pelo impulso proveniente do movimento denominado "novo institucionalismo', com sua ênfase cognitivista de explicação dos fundamentos da ação social (DiMaggio \& Powell, 1983; Meyer \& Rowan, 1977; Zucker, 1977). Apesar dessa nova ênfase, o novo institucionalismo mantém-se na tradição contingencialista de localizar no ambiente os elementos condicionantes da ação. Como afirmam DiMaggio e Powell:

o novo institucionalismo em teoria da organização e na sociologia compreende rejeição dos modelos de ator racional, interesse em instituições como variáveis independentes, mudança em direção a explicações cognitivas e culturais, e interesse em propriedades de unidades supra-individuais de análise que não podem ser reduzidas a agregados de, ou a consequiências diretas de atributos e motivos individuais (DiMaggio \& Powell, 1991, p. 8, grifos acrescentados).

Têm-se aqui pelo menos três importantes debates que passaram a nortear a teoria institucional em organizações nos últimos anos.

O primeiro desses debates segue tradição sociológica de se posicionar contra o paradigma da escolha racional. Predomina na teoria institucional em organizações o entendimento de que a capacidade de decisão racional dos sistemas é afetada pelas contingências de seu contexto (DiMaggio \& Powell, 1991; Machado-daSilva \& Fonseca, 1999; Meyer \& Rowan, 1977). Para Machado-da-Silva e Fonseca (1999, p. 31), "de acordo com os institucionalistas, as organizações estão insertas em ambiente constituído por regras, crenças e valores, criados e consolidados por meio da interação social. Nesse sentido, sua sobrevivência depende da capacidade de atendimento das orientações coletivamente compartilhadas [...]". Esse é um dos entendimentos centrais da perspectiva institucional, geralmente aceito explícita ou implicitamente sob o conceito de ambiente institucional (DiMaggio \& Powell, 1983; Machado-da-Silva \& Fonseca, 1999; Meyer \& Rowan, 1977; Scott \& Meyer, 1994; Tolbert, 1985). Nessa perspectiva de entendimento, entretanto, o ambiente institucional é definido como determinante do comportamento organizacional ou, pelo menos, como variável independente em relação a ele.

De forma ainda mais radical Zucker (1991, p. 83) vai pôr foco apenas no aspecto estruturante dos ambientes, quando admite que "[...] o conhecimento social, uma vez institucionalizado, existe como fato, como parte da realidade objetiva, e pode ser transmitido diretamente sobre esta base" (Zucker, 1991, p. 83). Tal concepção - cujos fundamentos são reconhecidamente vinculados à sociologia durkheimiana - tende a igualar elevado grau de institucionalização com reprodução direta do padrão social, resistência à sua mudança (Zucker, 1991) e constituição de hábitos de comportamento (Tolbert \& Zucker, 1996). Como afirmam DiMaggio e Powell 
(1991, p. 11), “arranjos institucionalizados são reproduzidos porque os indivíduos normalmente não conseguem sequer conceber alternativas apropriadas (ou porque eles tomam por irrealistas as alternativas que conseguem imaginar)". Entendido neste sentido, o ambiente institucional possui elevada força de difusão de padrões sociais de conhecimento, à semelhança do poder de difusão de padrões normativos na concepção de Parsons (1951). Aparentemente alguns estudos (Tolbert \& Zucker, 1983; Zucker, 1991) substituíram a supersocialização normativa por uma espécie de 'supersocialização cognitiva', seguindo a orientação de que padrões institucionalizados determinam a ação por determinarem a forma de perceber e interpretar a realidade. Assim, ações organizacionais são entendidas como necessariamente conectadas em elevado grau aos padrões institucionalizados (Tolbert \& Zucker, 1996).

Para Lourau (1995) essa perspectiva de entendimento da ordem institucional apenas como 'ordem instituída' (desconsiderando-se a contrapartida inerente ao conceito, isto é, o papel de agentes instituintes, no conceito daquele autor), constituiuse em um dos equívocos sociológicos desenvolvidos no estudo da questão e em relação ao qual se propõe, em seu estudo, contrapor, restituindo "... ao conceito de instituição sua significação dinâmica” (Lourau, 1995, p. 136). Para ele

à força de esvaziar o conceito de instituição de uma de suas instâncias primitivas (instituir no sentido de fundar, criar, romper com uma ordem antiga e criar uma nova), a sociologia acabou por identificar a instituição com a ordem estabelecida. Não é por acaso que, no momento em que esta ordem aparece a camadas sociais instituintes como unicamente repressiva, a palavra instituição parece designar apenas o instituído. Este erro teórico, que os revolucionários frequientemente cometem, tem como responsável a sociologia destes últimos cinqüenta anos (Lourau, 1995, p. 136).

De igual modo Oliver (1991) chama a atenção para o fato de que esta ênfase no caráter estruturante do ambiente que, conforme se vê parte na teoria das organizações, herdou da sociologia contemporânea, dificultou a análise da capacidade de ação estratégica dos atores sociais, nos estudos de alguns dos representantes da teoria institucional. Paralelamente à tal concepção quase supersocializada dos agentes e sistemas, vários outros autores vêm analisando a influência das instituições, sem negar algum grau de autonomia em face a elas. Surgem daí as noções de estrutura organizacional como simultaneamente estruturante das ações dos atores organizacionais e de igual modo estruturada por elas (Ranson, Hinings, \& Greenwood, 1980) e de imersão social (embeddedness) da ação em oposição, tanto à sua determinação quanto à sua liberdade absoluta (Granovetter, 1985), além da noção de instituição, como comportando em si tanto forças instituídas como instituintes, como se relatou, há pouco, com base em Lourau (1995). 
Granovetter (1985) é outro autor que vai criticar a oposição estrita entre o social e o individual. Para ele as concepções de ação subsocializadas e super socializadas se igualam no seu pressuposto de atomização: o entendimento de que ações individuais são determinadas por estruturas normativas do ambiente tem por pressuposto a idéia de que a internalização dos valores sociais se dá de modo tão profundo, que os indivíduos agem como se tais valores fossem seus, ou seja, sem consciência de sua procedência social; isto parece válido também para as versões mais radicais do novo institucionalismo cognitivista. $O$ desafio proposto, então, é definir o processo pelo qual instituições afetam a ação sem, entretanto, sucumbir a uma ou outra versão atomista da ação. Vários autores no âmbito da teoria organizacional vêm propondo respostas para esse desafio, em especial porque ele representa limitação da teoria organizacional, ao sugerir que sejam mutuamente excludentes as abordagens institucional e estratégica em organizações (Barley \& Tolbert, 1997; Machado-da-Silva, Fonseca, \& Crubellate, 2005; Oliver, 1991, but also Meyer \& Rowan, 1977; Scott, 1994, 1995; Westphal \& Zajac, 2001).

Talvez o melhor modo de descrever a dicotomia que, em alguns momentos, se identificou na teoria institucional, conforme há pouco mencionado, é dizer que ela se ampara em conflito ainda latente na teoria institucional das organizações a respeito da natureza de atores e sistemas sociais e de sua relação com seus ambientes. Tal conflito permeia a noção de sistemas fechados e racionais, constituintes de seus ambientes versus a noção de sistemas abertos, constituídos por seus contextos ambientais. A consideração dos vários e recentes esforços para a superação dessa dicotomia no âmbito da teoria social e da teoria institucional das organizações, conforme acima se evidenciou, não diminui a importância de outras e diferentes alternativas para analisar tal conflito.

Um segundo debate compreende as supostas ênfases predominantes na teoria institucional das organizações. Para DiMaggio e Powell (1991, p. 15), uma das distinções fundamentais entre os chamados velho e novo institucionalismos pode ser assim descrita: "não normas e valores mas scripts, regras e classificações taken for granted são o material de que instituições são feitas". Igualmente afirmam Tolbert e Zucker (1983, p. 25): "institucionalização é um processo cognitivo".

Para Selznick (1996, p. 274) a ênfase cognitivista, suposta como marca do novo institucionalismo, não é tão inovadora como de início possa parecer, uma vez que corresponde à noção interpretativista: "[...] a interação entre cultura e organização é mediada por uma mente socialmente construída, isto é, por padrões de 'percepção e avaliação"'. Talvez em função da sua declarada base weberiana (evidente no argumento de Selznick), o autor que mais parece ter caminhado no 
sentido de integração das várias noções do fenômeno das instituições é Scott (1994, 1995, 2001), para quem tais instituições compreendem sistemas de significados que "[...] incorporam regras representacionais, constitutivas e normativas" (Scott, 1994, p. 60) ou, "estruturas e práticas cognitivas, normativas e regulativas que provêem estabilidade e significado ao comportamento social" (Scott, 1995, p. xiii).

Mas, apesar de seu escopo integrativo, o modelo de Scott $(1995,2001)$ mantém ainda os elementos institucionais, como estruturas conceitualmente segmentadas, sem vislumbre suficientemente claro de sua integração no plano real, o que parece ser indicativo de espaço para tentativas de exploração desse conflito na teoria institucional, que afinal repousa na própria definição do que consiste, em última instância, esse fenômeno social, qual sua substância e sua dinâmica concreta.

O terceiro conflito anteriormente mencionado se refere ao nível social de ocorrência do processo de institucionalização. Para DiMaggio e Powell (1991, p. 15) “[...] instituições são abstrações no nível macro [social]". Mas como aponta Scott (2001), essa ênfase no nível macrossocial, como locus do processo de institucionalização, não é único na teoria institucional mais recente. Para ele, "enquanto Meyer e Rowan desenvolveram o lado macro do argumento [institucional], Zucker [...] enfatizou as microfundações das instituições" (Scott, 2001, p. 43).

Para Zucker (1991) a predominância de análises institucionais no nível macrossocial decorre do foco no conteúdo das instituições. Ela, por sua vez, indica que o foco analítico no nível microssocial predominante em seus estudos decorre de sua maior preocupação com o processo de institucionalização que, aliás, permanece mal compreendido. Também é importante sua sugestão de que os estudos institucionais com foco macroanalítico adotam como objeto de pesquisa não o processo e sim os efeitos da institucionalização, não permitindo que se perceba que "[...] institucionalização é uma variável contínua mais do que binária" (Zucker, 1991, p. 104). Para Zucker a institucionalização ocorre sempre no plano local ou mesmo individual, devendo-se negar a possibilidade de resistência individual a padrões altamente institucionalizados (no sentido do decoupling operacional suposto por Meyer \& Rowan, 1977). Essa forma de entender instituições também exclui a possibilidade de diferentes planos sociais em que pode ocorrer o processo de institucionalização, ao admitir apenas as relações interpessoais (plano micro) como locus da institucionalização.

De qualquer modo, há aqui um conflito na teoria institucional das organizações a respeito do plano social adequado para a análise dos processos de institucionalização e que tem como uma de suas importantes consequiências a própria definição dos possíveis efeitos desse processo, com reflexo na coerência 
ou não da suposição de algum espaço de autonomia individual (e ação estratégica) em relação a padrões altamente institucionalizados, questão anteriormente levantada.

Note-se, contudo, que tais oposições são peculiares (ou assim ainda permanecem) aos estudos institucionais na teoria das organizações. Fora desse escopo, esta visão dicotômica já é considerada por alguns autores como em processo de superação. Assim é que Lourau (1995), por exemplo, em sua análise institucional, discute algumas das questões aqui ponderadas da perspectiva de uma suposta oposição entre particularidade e universalidade. Para ele

É comum confundir-se particularidade e singularidade, opondo-se artificialmente o geral (ou universal) ao particular, esquecendo que esta oposição é puramente abstrata, não existe nunca na prática, mas somente na ideologia e na filosofia idealista. (...) Com a oposição do particular ao geral a dialética dá lugar a antinomias 'racionais', 'naturais' ou 'fatais' entre o indivíduo e a sociedade (ou 'o mundo'), antinomias que se resolvem ou pela preponderância concedida à sociedade ou pela preeminência atribuída ao indivíduo (Lourau, 1995, p. 10).

Parece evidente que parte da teoria institucional das organizações ainda não superou o estágio das oposições racionais ou naturais entre as categorias de objetividade e subjetividade, organização e ambiente, indivíduo e sociedade, entre outras. Possibilidades de avanço no sentido de solução destes outros conflitos parecem estar contidas na teoria dos sistemas sociais, e é esta expectativa que se pretende evidenciar a seguir.

\section{Três Conceitos em Teoria Neofuncionalista}

O neofuncionalismo tem em Niklas Luhmann $(1983,1989,1995)$ a sua principal expressão, constituindo-se em radicalização do funcionalismo: “[...] Luhmann reúne condições para inverter a ótica estrutural-funcional parsoniana, ao deslocar a questão de quais as funções requeridas pelo sistema para a questão de como este é levado a responder a exigências funcionais, vale dizer, operacionais de funcionamento" (Cohn, 1998, p. 58). O mesmo autor afirma ainda que

a partir do momento em que cabe ao sistema responder a exigências funcionais, e essas exigências derivam de relações com um ambiente marcado pela contingência (incapaz, portanto, de orientar a constituição mais adequada do sistema) este enfrenta uma tarefa nova: a de criar por sua conta os seus próprios elementos, realizar operações autoconstitutivas [...] (Cohn, 1995, p. 58). 
Além da noção de autopoiese, outras noções neofuncionalistas se encontram evidenciadas nessa descrição, como as idéias de complexidade e diferenciação e a própria definição de sistemas sociais como sistemas simultaneamente abertos e fechados; sobre isso se discorre a seguir, sendo esta uma noção fundamental para os propósitos deste ensaio.

\section{Sistemas Sociais como Sistemas Fechados e Abertos}

Para a teoria sistêmica convencional (Bertallanfy, 1975; Katz \& Kahn, 1976), os sistemas devem ser analisados tendo como base a suposta distinção fundamental de sua abertura (no caso dos sistemas permeáveis) versus fechamento (no caso de sistemas isolados) em relação ao contexto ambiental, não se admitindo, em geral, a validade lógica ou conceitual de definições intermediárias.

Mas para Luhmann (1989) a natureza autopoiética dos sistemas sociais exige entendê-los como sistemas simultaneamente abertos e fechados. Ainda para ele sistemas são conjuntos de elementos em interação, incluindo aquelas interações que, por sua vez, constituem o mecanismo básico a partir do qual os sistemas se conformam a si mesmos, em contínua diferenciação em relação ao ambiente, enquanto se reproduzem. Luhmann segue a definição de Humberto Maturana e também entende sistemas como sendo autopoieticamente constituídos, o que significa que eles consistem em "redes de produções de componentes que recursivamente, através de suas interações [isto é, as interações daqueles componentes], geram e realizam a própria rede que os produz e os constitui" (Maturana como citado em Knodt, 1995, p. xx). Nesta definição de sistemas está também implícita a definição de autopoiese, isto é, o processo mediante o qual os sistemas vivos se constituem de modo fechado sobre si mesmos ou, organizacionalmente fechado e que está na base da sua própria conservação. Pode ser dispensável, mas parece apropriado esclarecer que, desta forma, os sistemas são mais do que o mero ajuntamento mecânico de suas partes: na concepção de Luhmann, é o processo de autopoiese que dá aos sistemas sua dinamicidade e organicidade.

Luhmann $(1989,1995)$ aplica esta idéia a sistemas sociais: economia, política, religião, arte, educação, organizações e a própria sociedade. Para ele sistemas sociais “...vêm a existir sempre que uma conexão autopoiética de comunicações ocorre e distingue a si mesma em relação a um ambiente por meio da restrição das comunicações apropriadas" (Luhmann, 1989, p. 145). Eles têm, portanto, como ponto central de sua natureza, a capacidade de processamento de significados e da sua comunicação, mediante a qual se reproduzem. Os sistemas sociais se 
diferenciam uns dos outros por meio de codificação específica a cada sistema, o que, por sua vez, constitui o seu cerne organizativo por meio do qual "[...] um sistema pode mudar estruturas sem perder sua identidade codificada" (Luhmann, 1989, p. 45). Com isso, "[...] um sistema adquire a possibilidade de operar como sistema simultaneamente fechado e aberto" (p. 45 - itálico no original), isto é, como sistema que incorpora em sua estrutura as pressões do contexto ambiental, sem se diluir no ambiente, sem alterar sua organização.

Sistemas sociais são, então, sistemas autopoiéticos, o que significa que são operacionalmente fechados. Isto não implica, por sua vez, que não possam ser afetados de modo algum pelo ambiente. Significa, sim, que tais sistemas são 'cegos' em relação ao que acontece além de suas fronteiras ou, em outros termos, não podem receber informação direta do ambiente, e reagir diretamente a ele. Enquanto unidade autônoma, um sistema social qualquer " [...] pode reagir ao seu ambiente apenas de acordo com seu próprio modo de operação, o modo peculiar a ele" (Bednarz Jr., 1989, p. xiii).

Esse modo peculiar de operação tem como fundamento, nos sistemas sociais, o processo de significação. Assim, informações presentes no ambiente não fluirão diretamente através das fronteiras do sistema, para o qual elas serão algo como uma perturbação (Luhmann, 2002) que faz disparar o processo de significação que é, como já se antecipou há pouco neste ensaio, por meio da definição de sistema, interno e sempre auto-referente: "Significado sempre se refere a significado [...] Sistemas cujos limites são o significado não podem nunca experimentar ou agir de qualquer forma que seja livre de significado" (Luhmann, 1995, p. 62). Como consequiência, "em princípio, tudo é acessível a sistemas de significado, mas somente na forma de significado [...] tudo o que pode ser percebido e processado no mundo dos sistemas de significado deve assumir a forma de significado" (Luhmann, 1995, p. 63).

Em resumo, sistemas sociais são estruturalmente adaptáveis ou abertos, porque são, ao mesmo tempo e necessariamente, operacional ou organizacionalmente fechados. Eles se comunicam de algum modo com seu ambiente apenas na medida em que eles próprios, de forma auto-referida, produzem ou selecionam internamente os significados a que irão responder e que serão utilizados para configurar e reconfigurar as fronteiras entre sistema e ambiente (Luhmann, 1989, 1995; Paterson, 1997). Isso implica então que o próprio sistema se produz e também produz seu próprio ambiente, porque é ele que, em última instância, define suas fronteiras.

Tais apontamentos resultam também em implicações para a noção de relacionamento contingencial entre sistemas e ambientes, o que se irá discutir a seguir. 


\section{Sistemas e Ambientes: Dupla Contingência}

O segundo conceito neofuncionalista que se pretende discutir deriva das conclusões acima apresentadas. Quando se conclui que sistemas sociais são abertos e fechados, torna-se possível rever a idéia tradicional de contingência. Convencionalmente se toma a relação de contingência como unidirecional, o que quer dizer que se admite apenas que ambientes afetam os sistemas ou, em outros termos, que apenas os sistemas lidam com o risco inerente às escolhas e à possibilidade de desapontamento, em face das várias opções oferecidas pelo ambiente. Para Luhmann (1976, p. 96), "tornou-se costume explicar organizações por algum tipo de 'teoria da contingência' [...] Isto significa que diferenças na estrutura das organizações podem ser explicadas por diferenças nos seus ambientes". Fundamental para essa perspectiva é a noção metodológica de ambiente como conjunto de variáveis independentes e organizações como conjunto de variáveis dependentes. Assim, vê-se que

[...] a teoria da contingência desenvolve duas noções diferentes: (1) dependência e (2) incerteza, lado a lado. Por um lado contingência significa que as estruturas e práticas [...] de um sistema dependem da forma pela qual o ambiente se torna relevante para o sistema, enquanto a situação reversa - o sistema operando sobre o ambiente - não é geralmente levada em conta (Luhmann, 1976, p. 97).

Desse modo, contingência fica sendo entendida como oposto de necessário. Ser contingente implica que havia outras possibilidades que não se confirmaram ou, "algo é contingente na medida em que não é nem necessário nem impossível" (Luhmann, 1995, p. 106) e também implica analisar a relação entre fatos, uma vez que, da perspectiva do sistema, as variáveis ambientais são reconhecidas desta forma (como independentes e, assim, como fatos).

Mas como se observou anteriormente a relação entre ambientes e sistemas não é direta, nem baseada no fluxo de informações do ambiente para o sistema social. Informação não é conceito apropriado para o ambiente, uma vez que ela é o produto da interpretação sistêmica (Luhmann, 2002). Informações, portanto, são sempre significativas. Os 'dados' presentes no ambiente, para que afetem de algum modo o sistema, terão de ser convertidos em informações, uma vez que, no âmbito do sistema, o que flui são significados, de modo que o ambiente - da perspectiva do sistema - constitui-se naquilo que é seletivamente percebido e interpretado pelo sistema (Luhmann, 1995; também Weick, 1969), mediante processo que é necessariamente fechado. De igual modo a própria noção de ambiente só pode ser estabelecida a partir do sistema como ponto referencial, de modo que se torna coerente afirmar que o ambiente é (conceitualmente) produto do sistema. 
Para entender melhor essa possibilidade deve-se recorrer ao sentido atribuído ao termo 'significado', que é a diferença entre o real e suas várias possibilidades (Luhmann, 1995, 2002). O significado do real depende de suas outras possibilidades, na perspectiva de quem o está definindo. Tem-se como conseqüência que o que é real no ambiente (tanto quanto no sistema) é sempre provisoriamente definido, dependente de com que outra das suas possibilidades ele está sendo relacionado. Portanto, o ambiente também é contingente - também depende do sistema e também subjaz ao risco e à possibilidade de frustração em relação ao sistema.

Luhmann (1976, p. 105) resume tal noção circular por meio do termo 'dupla contingência' e propõe revisão da noção contingencial, sugerindo-a como relação "[...] não entre fatos, mas entre contingências. Eles [sistema e ambiente] podem variar nos dois sentidos [...]". Por exemplo, regras em organizações "[...] são concebidas para governar o comportamento de seus membros. Mas as regras são contingentes também. Elas só adquirem significado e valor positivo através de decisões, o que implica que elas podem ser alteradas [...]" (Luhmann, 1976, p. 99). Nesses termos a regra só será efetiva enquanto tal na medida em que for 'significada' e, portanto, adquirir algum sentido para atores sociais. As implicações disto para a teoria institucional (e a teoria organizacional de modo geral) são antecipadas parcialmente por Luhmann:

[...] os próprios sistemas organizacionais reagem à diferença entre eles e seus ambientes na base de suas escolhas estruturais, a partir do fato de que estruturas ambientais e estruturas sistêmicas, algumas vezes, variam ou podem ser modificadas, tanto dependendo quanto independendo umas das outras. Esse parece ser o foco especial sobre aquilo em que os sistemas organizacionais se diferenciam; a racionalidade peculiar de sua auto-organização e gestão é que eles abraçam a dupla contingência das relações ambiente-sistema e a levam adiante (Luhmann, 1976, p. 108).

\section{Expectativa de Expectativas ou, Instituições como Economia DE Consenso}

O terceiro conceito a ser aqui apresentado tem relação com a noção de dupla contingência. Deve-se notar que, se a relação entre sistema e ambiente pode ser contingente em ambas as direções, ela passa a ser mais bem descrita não como relação que se origina em qualquer possibilidade de determinação de respostas ou de comportamentos, senão apenas como relação baseada em expectativas ou, enquanto relação sempre de alto risco de frustração, não ocorre em função de certezas, mas apenas de confiança. Luhmann afirma que 
uma das mais importantes conseqüências da dupla contingência é a emergência de confiança e desconfiança. Quando o entrar em situação de dupla contingência é experimentado como particularmente arriscado, elas aparecem. O outro pode agir de outra forma da que eu esperava precisamente se e porque ele sabe o que eu espero (Luhmann, 1995, p. 127, itálico no original).

Em função deste risco evidente (no limite, paralisante) a idéia de que a relação entre sistema e ambiente é duplo-contingente torna também coerente que se identifiquem processos pelos quais algum grau de confiança quanto ao fato de estarem corretas as expectativas (tanto da parte do sistema quanto da parte do ambiente) venha a emergir e a se estabelecer. A relação entre sistema e ambiente, enquanto relação duplamente contingente e, assim, de alto risco, implica relação entre expectativas. Em resumo, é relação baseada em 'expectativas de expectativas', e não apenas em expectativa de comportamentos. Assim,

sob as condições de dupla contingência [...] todo experimentar e agir social possui dupla relevância: uma no nível das expectativas imediatas de comportamento, na satisfação ou no desapontamento daquilo que se espera do outro; a outra em termos de avaliação do significado do comportamento próprio em relação à expectativa do outro (Luhmann, 1983, p. 48).

Para que ocorra a possibilidade de um sistema engajar-se em interações sociais, portanto, é necessário "[...] ter expectativa sobre a expectativa que se tem dele" (Luhmann, 1983, p. 48). A própria existência de expectativas já possui valor estrutural, por permitir alguma segurança de ação (Luhmann, 1995). A diminuição das incertezas, entretanto, provém da estabilização ou generalização das expectativas (Luhmann, 1995), que tem, por sua vez, dupla função.

Por um lado, ela executa uma seleção dentro da totalidade de possibilidades indicadas [...]. E por outro lado, ela une descontinuidades em questões factuais, temporais e sociais, de modo que uma expectativa pode ainda ser usada quando a situação muda (Luhmann, 1995, p. 97).

Em síntese, a estabilização e a generalização de expectativas facilita a seleção de alternativas em relação a uma realidade complexa e também une descontinuidades em que a existência de alguma relação não é necessariamente evidente (ou em que talvez ela não exista de fato).

Ainda para Luhmann (1983, p. 52), a norma e o próprio Direito deveriam ser entendidos sob este prisma, não tendo como função única ou principal tornar os comportamentos previsíveis e sim compatibilizar expectativas recíprocas, “[...] regular a expectativa sobre expectativas [...] criando [...] segurança em termos de expectativas". Mas a norma e o Direito podem sofrer adequação por meio de 
entendimentos mútuos a respeito de comportamentos que os alterem, modifiquem ou transgridam, disso dependendo então a sua própria vigência. Outro elemento social é incluído por Luhmann (1989) para a análise dessa estabilização: a figura de terceiros (além dos que esperam e dos que cumprem ou violam a regra, aqueles que não têm relação direta com a interação social específica, mas que detém expectativas quanto a ela - por exemplo, quanto ao cumprimento ou não da norma). É função de terceiros, segundo Luhmann (1983, p. 79), dar sustentação às instituições, mas isso ocorre de modo indireto, porque é a sua "suposta opinião [que] sustenta a instituição", de modo que quem age, age com base nas expectativas que tem a respeito das expectativas supostas em terceiros, e não em resposta direta a qualquer obrigação imposta nem mesmo apenas com base nas expectativas supostas naqueles com quem interage diretamente.

Institucionalização, neste sentido, não se define como generalização do consenso e sim como generalização de expectativa quanto à expectativa de consenso (ou, do consenso presumido em terceiros):

a função das instituições reside menos na criação e mais na economia do consenso, que é atingida na medida em que o consenso é antecipado na expectativa sobre expectativas, ou seja, como pressuposto, não mais precisando, em geral, ser concretamente expresso (Luhmann, 1983, p. 80).

Evidencia-se, assim, certa natureza dupla das instituições: enquanto tendo referência a terceiros, qualquer instituição é sustentada por mecanismo normativo. Por ouro lado, seguir ou não a tais expectativas supostas em terceiros ainda é uma questão de possibilidade, nunca de determinação. A sua existência "[...] não obriga à obediência [...] Mas ela motiva aquele que não queira arcar com as conseqüências, a não expressar sua discordância, estruturando assim as chances de comunicação no sentido da instituição" (Luhmann, 1983, p. 83). Deste modo, fica evidente também um mecanismo cognitivo de sustentação das instituições, que não poderia ser diferente em função da natureza operacionalmente fechada dos sistemas sociais e que implica a construção cognitiva de significados (neste caso, expectativas presumidas em terceiros são, em resumo, estruturas normativas processadas por meio de significados, e as expectativas quanto àquelas expectativas presumidas são, por sua vez, provenientes de processos cognitivos). Pode-se concluir que

esse mecanismo da institucionalização não estabiliza sem mais nem menos, [...] mas inicialmente estabiliza apenas hipóteses de continuidade [...]. Nessa acepção, o conceito de instituição possui sua característica específica não na compulsão social, não na ampliação do consenso faticamente concretizado, e também não na normatividade das expectativas [...] sua função reside em uma distribuição tangível de encargos e riscos comportamentais, que tornam provável 
a manutenção de uma redução social vivenciada e que dão chances previsivelmente melhores a certas projeções normativas. Aquele cujas expectativas sejam contrárias à instituição terá contra si o peso de uma autoevidência presumida (Luhmann, 1983, p. 81).

Parece plausível admitir, portanto, que tal mecanismo é simultaneamente coercitivo, normativo e principalmente cognitivo. O conceito de expectativa, bem como os dois outros conceitos antes resumidos, esclarece aspectos da teoria institucional e pode representar alternativa analítica, como se espera discutir mais extensamente na sessão seguinte do ensaio.

\section{Contribuições Neofuncionalistas à Teoria Institucional e à Teoria das Organizações}

O neofuncionalismo compreende tendências teóricas diversas para elaborar uma teoria geral dos sistemas sociais. Nesse sentido, atende à orientação de Münch (1999, p. 201) a respeito de um “[...] paradigma compreensivo com um quadro de referências em que se preservem os postulados de todas essas abordagens [analisadas por aquele autor]" e "capaz de abarcar os diversos campos institucionais a que as abordagens específicas se propõem dar explicações adequadas". Com relação aos três conflitos na teoria institucional das organizações, com os quais se iniciou este ensaio, parece possível observar que o neofuncionalismo sugere alternativas de síntese entre as opções dicotômicas.

As noções de abertura e fechamento sistêmico, de dupla contingência e de expectativas de expectativas institucionalizadas lançam luzes sobre a natureza das instituições, o processo de institucionalização e, em conseqüência, sobre os processos e estruturas organizacionais enquanto processos e estruturas em institucionalização. Com relação ao primeiro dos conflitos - a relação entre sistemas sociais e o ambiente institucional - parece possível admitir que, na perspectiva neofuncionalista, tanto o sistema demanda padrões ambientais institucionalizados como recurso que dá impulso inicial à ação, quanto aqueles mesmos padrões somente adquirem algum grau de institucionalização como resultado das ações dos sistemas implicados.

A diferença entre Luhmann (1989, 1995) e Granovetter (1985) parece estar no grau em que a relação para com o ambiente se dá de modo voluntário (em Granovetter) versus uma visão de autonomia não voluntária (em Luhmann), em que tal relação ocorre como processo de comunicação sempre que há eventos ambientais que 'disparam' a interpretação auto-referente inerente ao sistema. A 
diferença mais importante talvez seja que, de acordo com a noção de 'embeddedness', os significados são relativamente livres, no sentido de que eles são construídos livremente, na medida em que agentes interagem socialmente. Já em Luhmann, os significados possuem núcleo que é próprio de cada tipo de sistema social, o que é sintetizado em sua teoria pela idéia de codificação. Um sistema social possui um código binário exclusivo em torno do qual ocorre a significação e interpretação dos eventos externos e a própria construção do seu ambiente (ver principalmente Luhmann, 1989). Assim, na teoria neofuncionalista o processo de significação não é tão livre quanto na sociologia de Granovetter, ainda que seja concebido como plenamente autônomo.

Para parte da teoria institucional essa noção desafia tanto a perspectiva racionalista, porque se torna inviável pensar em agentes construindo voluntariamente os padrões institucionais, tendo como referência seus interesses e como limite apenas os demais agentes auto-interessados, quanto a perspectiva de instituições como fonte direta dos motivos da ação dos agentes sociais, seja por meio de determinações normativas ou condicionamentos culturais-cognitivos. Tais perspectivas focadas exclusivamente em ação ou em estruturas sociais, do ponto de vista neofuncionalista, não têm sentido (Cohn, 1998): as instituições são produtos autônomos - mas não totalmente voluntários - dos atores sociais (pessoas e sistemas) nelas implicados, direta ou indiretamente e, ao mesmo tempo, são o recurso por meio do qual aqueles atores se reproduzem enquanto sistemas psíquicos (pessoas) ou sociais. Em resumo, não se pode analisar um padrão ambiental sem analisar as ações que o constituem, sustentam ou alteram, como se fosse um estado final, 'congelado', independente. De igual modo, não há sentido em se analisar ações de modo isolado, como se não demandassem o estímulo ou 'perturbação' e a estabilização, proporcionados por padrões ambientais.

Para a teoria institucional em organizações uma das principais implicações disto é que se deve abandonar definitivamente a oposição entre análise institucional e estratégica das organizações, substituindo-a pelo pressuposto de que, para que se entendam as ações organizacionais, instituições e estratégias devem ser analisadas nas suas interações. Instituições somente adquirem a suposta estabilidade que as caracteriza mediante a contínua reação estratégica dos atores e sistemas sociais por elas afetados, que as toma como base de ação e as reforça ou questiona por meio das próprias respostas que elas estimularam. De igual modo, aquelas ações ou reações estratégicas não ocorreriam sem o horizonte e o impulso proporcionado pelos padrões em institucionalização. Instituições e estratégias são co-dependentes, faces de um processo único, contínuo, sempre inacabado. Para Münch (1999, p. 204) tal relação refere-se ao fato de que "[...] toda ação concreta envolve um tecido complexo de microinteração e macro-relações, de sorte que as duas 
perspectivas devem concorrer para a análise". Assim, a abordagem conjunta dos dois fenômenos não é apenas uma opção teórica, mas alternativa promissora para a análise organizacional.

As noções neofuncionalistas analisadas neste artigo, em especial a idéia de dupla contingência, parecem sugerir um foco analítico mais produtivo que recaia sobre o processo de institucionalização e não sobre a localização de instituições concretas específicas e de seu impacto sobre atores e sistemas sociais e isso porque, da perspectiva daquelas noções, a suposição de que instituições se cristalizam de modo definitivo é pouco provável. Mais produtivo seria tomar o processo institucional no sentido de um 'processo-sempre-em-construção', em contínua formação e desconstrução, enfim, que sempre possui um lado concreto e exterior (no plano macrossocial) cuja permanência é provisória, sejam elementos regulativos, normativos ou padrões institucionalizados de cognição, exatamente porque depende das relações travadas no cotidiano (no plano microssocial) entre os atores por eles afetados e das respostas oferecidas por aqueles atores, tanto de conformidade quanto de resistência (Oliver, 1991; Scott, 2001), dependendo dos significados a eles atribuídos.

A noção construtivista subjacente ao conceito de dupla contingência sugere que numa perspectiva neofuncionalista seria apropriado caracterizar o processo institucional como referindo-se à estruturação sempre contínua e provisória dos padrões institucionais e as ações sempre autônomas dos sistemas, ações estas afetadas por e constituídas com base nos padrões em estruturação, mas sempre auto-referentes e, portanto, operacionalmente fechadas em torno dos significados internos aos próprios sistemas.

Tal modelo lembra uma espiral contínua de elaboração das fronteiras entre sistema e ambiente e que se desenvolve na medida em que o sistema se constrói por meio de conformidade ou diferenciação (nas organizações, por meio de suas respostas estratégicas), em relação a aspectos ambientais a que o próprio sistema dá significado. Neste sentido(2), uma instituição nunca é "[...] o estágio final de um processo de institucionalização" (Tolbert \& Zucker, 1996, p. 204), mas sempre um estado provisório e, em termos conceituais, um artifício usado para delimitar o processo que, de fato, é contínuo. Assim, sua análise empírica exigiria ir além dos aspectos formais ou explícitos dos elementos institucionais para analisar também e necessariamente os aspectos do cotidiano das reações estratégicas que surgem em resposta àqueles elementos e que, ao mesmo tempo, os reconstitui.

Estas noções sistêmicas põem em dúvida também o papel regulador ou controlador das instituições, sugerindo que mesmo elevados graus de institucionalização não significarão respostas automáticas, seja no plano normativo 
ou cognitivo e, principalmente, se a referência for a padrões sociais regulativos, impostos coercitivamente. Como se observou anteriormente, a função das instituições não está no controle do comportamento e sim no aumento da confiança, que ocorre quando se estabilizam as expectativas quanto a expectativas supostas em terceiros. Tal estabilização oferece um horizonte mais claro e torna mais provável (não mais que isso) certos tipos de respostas.

Não se deve esperar que uma regra social nasça com a estabilidade que caracteriza os padrões institucionalizados. Esses padrões, como ressalta Scott (1994, 1995, 2001), são elementos institucionais, mas não constituem em si instituições. Num sentido neofuncionalista, o processo institucional deveria ser entendido como compreendendo dois aspectos. O primeiro corresponderia a quais elementos sociais estão institucionalizando-se. Por exemplo, quais aspectos de uma nova lei ou política governamental ou, ainda, de um plano organizacional, estão recebendo que tipo de respostas dos agentes e sistemas a que se destinam e que suposta ou pretensamente devem regular. $\mathrm{O}$ segundo corresponderia ao plano social em que ele adquire estabilidade: como já se observou anteriormente a idéia de institucionalização aqui implica tanto expectativas no plano macrossocial quanto expectativas de expectativas, no plano microssocial. Uma lei pode existir e nunca afetar de nenhum modo o comportamento de alguns sistemas ou agentes sociais, ou pode afetá-los de modo diferente do que inicialmente poderia estar contido no texto da lei como expectativa, e isso graças ao próprio processo de sua institucionalização, o mesmo acontecendo com valores, crenças ou tipificações socialmente generalizados.

Nessa perspectiva, a crítica de Tolbert e Zucker (1996) a Meyer e Rowan (1977), concernente à possibilidade de ações desconectadas em relação a padrões altamente institucionalizados só tem sentido, quando se pensa em instituições enquanto fatos sociais que podem alcançar tão elevado grau de estabilização a ponto de se tornarem objetivadas, determinando comportamentos e significados. Se as instituições são pensadas enquanto processo contínuo, enquanto possibilidade ou enquanto estabilização da hipótese de sua continuidade por meio de expectativas generalizadas (Luhmann, 1983), então não se deve admitir aquele grau de determinação como próprio do fenômeno institucional. $\mathrm{Na}$ teoria neofuncionalista, as instituições deixam de ser entendidas como compreendendo consenso de fato. Elas implicam apenas expectativa de consenso e, então, sua estabilização e continuidade são sempre provisórias e seu impacto sobre as ações nunca é de natureza exclusiva, porque, mesmo quando ocorre imposição coercitiva, há ainda que ocorrer sua interpretação no âmbito cognitivo e sua estabilização no plano normativo. Como tal, elas podem vir a sofrer resistência - explícita ou velada - a qualquer momento, desde que haja atores sociais dispostos a assumir os riscos presumidos em tal 
comportamento e arcar com a responsabilidade da desestabilização dos parâmetros supostos tacitamente ou aceitos expressamente (Luhmann, 1983).

Desse modo, um acoplamento frouxo (loose coupling) é sempre esperado em relação a qualquer parâmetro em institucionalização, uma vez que a ação é produto da sua interpretação pelo sistema. Por essa mesma razão uma 'correlação ponto a pontó é o que menos se espera em relação a qualquer tipo de padrão institucional (conforme Luhmann, 1989; Meyer \& Rowan, 1977 e também Weick, 1969), menos ainda que a sua rejeição completa. A sua rejeição completa é pouco provável, sendo mais difícil, na medida em que mais se encontre estabilizado socialmente o padrão institucional. O grau de correlação, em resumo, dependerá principalmente de lógica interna dos próprios sistemas implicados (Machado-daSilva \& Fonseca, 1999; Meyer \& Rowan, 1977; Selznick, 1996), em função de interesses e padrões perceptivos e interpretativos (Scott, 2001) que os levem a atrelar àqueles padrões institucionais significados condizentes ou não com suas pretensões de eficiência técnica, liderança ou simples obtenção de legitimidade social, entre outras.

Pode-se concluir que nesta perspectiva a correlação entre estruturas e ações organizacionais e forças institucionais é circular: as estruturas e ações são orientadas por forças ambientais. Por outro lado, essas forças ambientais entram em processo de institucionalização, quando ocorre certo grau de correlação, ou seja, quando se responde positivamente a elas.

Quando se entende uma instituição não como estado final e sim como estabilização provisória de expectativas de consenso, torna-se mais fácil entender por que elas não determinam a ação. Se as ações dos sistemas são baseadas em expectativas (plano microssocial) de expectativas presumidas em terceiros (plano macrossocial), então na medida em que aquelas expectativas de terceiros estiverem institucionalizadas em grau elevado, maior será a possibilidade de que se desenvolvam expectativas coerentes quanto a elas. Desse modo, é que as instituições afetam a ação, sem determiná-la. Tal mecanismo ajuda a entender como se pode pensar na reprodução de padrões e ações sociais, sem que se venha a sucumbir à idéia de determinação ambiental das ações, pois se trata aqui mais de aumento da segurança cognitiva e normativa, quanto às expectativas presumidas, do que reprodução direta de padrões sociais ou comportamentos externamente ditados. Neste sentido ainda, a consequiência das instituições está mais em prover aquele tipo de estabilidade de expectativas do que em ditar padrões homogêneos que são muito mais ficção que fato (Luhmann, 1983).

Essa ecologia das instituições poderia ser resumida na lógica pela qual padrões sociais de natureza regulativa, normativa e cognitiva passam a ser considerados 
como apoiados pela opinião geral, por terceiros e, portanto, adquirem força social, ao serem presumidos como consensuais.

A noção institucional aqui proposta compreende o fato de que qualquer dos elementos institucionais (conforme Scott, 1995) adquire alguma relevância e capacidade de afetar os sistema sociais exatamente porque - e na medida em que - são percebidos e interpretados por aqueles sistemas. Mediante a percepção e a interpretação os elementos institucionais passam a ter algum significado da perspectiva dos sistemas, tornando-se mais ou menos relevantes em decorrência principalmente do significado a eles atribuído e das ações e reações que os sistemas elaboram como resposta a eles, sendo tais significados construídos com base na expectativa de consenso presumida em terceiros. Instituições são fenômenos sociais provisoriamente estáveis, sujeitas sempre a processo de construção social.

\section{Considerações Finais}

O que se tenta propor aqui não é a ruptura com explicações dadas à institucionalização de características organizacionais. Ao conjugar explicações neofuncionalistas e institucionalistas, não se quer formalizar nova teoria institucional, mas apresentar possibilidades de compreensão de fenômenos ainda sob análise no âmbito da teoria das organizações, principalmente a explicação do processo de institucionalização como processo que compreende níveis simultâneos de ocorrência. Tais aspectos já estão presentes na análise institucional feita por autores e pesquisadores de outros campos teóricos e por alguns autores dentro do campo das organizações; mas, ao que parece, esta não é ainda a vertente predominante dos estudos organizacionais, o que vem implicando a obsolescência do campo em algumas de suas análises ou, em outros casos, a superfluidade das críticas contra ele elaboradas.

Também, ao dar foco sobre a natureza simultaneamente cognitiva e normativa dos padrões institucionais, a teoria neofuncionalista parece indicar caminhos para a superação da dicotomia marcada por posições objetivistas de entendimento da realidade organizacional (quando tais organizações - e também as instituições são entendidas como fatos concretos e absolutamente externos às consciências individuais) versus posições que se apóiam exclusivamente na subjetividade do fenômeno organizacional e institucional e lhes negam qualquer elemento supraindividual. Entende-se que, na concepção neofuncionalista, o fenômeno institucional compreende uma dimensão normativa e, por isso, pelo menos intersubjetiva, porque as expectativas e valores emergem sempre da interação de agentes sociais, e 
também uma dimensão cognitiva, uma vez que aquelas mesmas expectativas e valores serão primeiramente percebidos e interpretados para que respostas sejam geradas.

Por outro lado, não se quer sugerir que a teoria neofuncionalista compreenda todas as possibilidades analíticas implicadas na perspectiva institucional. Constituise em mais uma forma possível de estudo do processo de institucionalização, com implicações, possibilidades e limitações específicas, mas certamente não a única perspectiva possível. A natureza complexa e multiparadigmática da abordagem neofuncionalista, entretanto, lança luzes sobre a lógica recursiva do processo de institucionalização, o que parece condizente com tendências da teoria social e com avanços teóricos e paradigmáticos já feitos em outras áreas do conhecimento humano e social há muito tempo, e em relação aos quais a teoria das organizações parece ainda carente de atualização.

Em resumo, o que se espera é que tal linha analítica, isto é, a abordagem do processo de institucionalização pela via teórica do neofuncionalismo luhmanniano, contribua para o esforço já presente de reexplicação de fenômenos organizacionais e sociais, acrescentando às perspectivas tradicionais novos horizontes explicativos e, como não poderia deixar de ser, também novas limitações.

\section{Artigo recebido em 21.02.2006. Aprovado em 30.05.2006.}

\section{Agradecimentos}

O presente trabalho foi realizado com apoio da CAPES, entidade do Governo Brasileiro voltada para a formação de recursos humanos.

\section{Notas}

${ }^{1}$ Este artigo rcebeu o prêmio de melhor trabalho do XXIX EnANPAD 2005 (Brasília, DF).

${ }^{2}$ Sugere-se o termo 'institutionalizing' para expressar o sentido processual implicado nesta descrição, à semelhança de Machado-da-Silva, Fonseca e Crubellate (2005) e seguindo a noção de 'organizing', proposta por Weick (1969). 


\section{ReferênCIAS BibliográficAs}

Barley, S., \&

Tolbert, P. (1997).

Institutionalization and structuration: studying the links between action and institution. Organization Studies, 18(1), 93-117.

Bednarz, J., Jr. (1989).

Translator's introduction. In N. Luhmann (Coord). Ecological communication (pp vii-xvi). Chicago: The University of Chicago Press.

Bertalanffy, L. (1975).

Teoria geral dos sistemas (2a ed.). Petrópolis: Vozes.

Boudon, R. (1998).

Limitations of rational choice theory. American Journal of Sociology, 104(3), 817-828.

Cohn, G. (1998).

As diferenças finas: de Simmel a Luhmann. Revista Brasileira de Ciências Sociais, 13(38), 53-62.

DiMaggio, P., \&

Powell, W. (1983).

The iron cage revisited: institutional isomorphism and collective rationality in organizational fields. American Sociological Review, 48(2), 147-160.

DiMaggio, P., \&

Powell, W. (1991).

Introduction. In W. Powell \& P. DiMaggio (Eds). The new institutionalism in organizational analysis (pp. 1-38). Chicago: The University of Chicago Press.
Granovetter, M. (1985).

Economic action and social structure: the problem of embeddedness. American Journal of Sociology, 91(3), 481-510.

Katz, D., \&

Kahn, R. (1976).

Psicologia social das organizações.

São Paulo: Atlas.

Lourau, R. (1995).

A análise institucional. Petrópolis: Vozes.

Luhmann, N. (1976).

A general theory of organized social systems. In G. Hofstede \& S. Kassem (Eds.). European contributions to organization theory (pp. 96-113). Amsterdam: Van Gorcum.

Luhmann, N. (1983).

Sociologia do direito I. Rio de Janeiro: Tempo Brasileiro.

Luhmann, N. (1989).

Ecological communication. Chicago: The University of Chicago Press.

Luhmann, N. (1995).

Social systems. Stanford: Stanford University Press.

Luhmann, N. (2002).

Theories of distinction. Stanford: Stanford University Press. 
Machado-da-Silva, C., \&

Fonseca, V. (1999).

Competitividade organizacional: conciliando padrões concorrenciais e padrões institucionais. In M. Vieira \& L. Oliveira (Eds.). Administração contemporânea: perspectivas estratégicas (pp. 27-39). São Paulo: Atlas.

Machado-da-Silva, C.,

Fonseca, V., \&

Crubellate, J. (2005).

Estrutura, agência e interpretação: elementos para uma abordagem recursiva do processo de institucionalização. Revista de Administração Contemporânea, 9(1 ${ }^{\text {a }}$ Edição Especial), 9-40.

Maturana, H. (2002).

Prefácio de Humberto Maturana Romesin à $2^{\mathrm{a}}$ edição. In H. Maturana \& F. Varela (Coords.). De máquinas e seres vivos ( $2 \mathrm{a}$ ed.). Porto Alegre: Artmed.

Meyer, J., \&

Rowan, B. (1977).

Institutionalized organizations: formal structure as myth and ceremony. American Journal of Sociology, 83(2), 340-363.

Münch, R. (1999).

A teoria parsoniana hoje: a busca de uma nova síntese. In A. Giddens \& J. Turner (Eds.). Teoria social hoje (pp. 175-228). São Paulo: Editora UNESP.

Oliver, C. (1991).

Strategic responses to institutional processes. Academy of Management Review, 16(1), 145-179.
Parsons, T. (1951).

The social system. New York: Free Press.

Paterson, J. (1997).

An introduction to Luhmann. Theory, Culture \& Society, 14(1), 37-39.

Ranson, S.,

Hinings, B., \&

Greenwood, R. (1980).

The structuring of organizational structures. Administrative Science Quarterly, 25(1), 1-17.

Scott, W. R. (1994).

Institution and organizations: toward a theoretical synthesis. In W. R. Scott \& J. Meyer (Eds.). Institutional environments and organizations: structural complexity and individualism (pp. 55-80). Thousand Oaks: SAGE.

Scott, W. R. (1995).

Introduction: institutional theory and organizations. In W. R. Scott \& S. Christensen (Eds.). The institutional construction of organizations (pp. xixxiii). Thousand Oaks: SAGE Publications.

Scott, W. R. (2001).

Institutions and organizations (2nd ed.). Thousand Oaks: SAGE.

Scott, W. R., \&

Meyer, J. (1994).

Institutional analysis: variance and process theory approaches. In W. R. Scott \& J. Meyer (Eds.). Institutional environments and organizations: structural complexity and individualism (pp. 81-112). Thousand Oaks: SAGE. 
Selznick, P. (1957).

Leadership in administration. New York: Row, Peterson and Co.

Selznick, P. (1966).

TVA and the grass roots. New York: Harper \& Row.

Selznick, P. (1996). Institutionalism "old" and "new". Administrative Science Quarterly, 41,270-277.

Simon, H. (1970). Comportamento administrativo (2a ed.). Rio de Janeiro: FGV.

Tolbert, P., \&

Zucker,L. (1983).

Institutional sources of change in the formal structure of organizations: the diffusion of civil service reform, 18801935. Administrative Science Quarterly, 28(1), 22-39.
Tolbert, P., \&

Zucker, L.. (1996).

The institutionalization of institutional theory. In S. Clegg, C. Hardy, \& W. Nord (Eds.). Handbook of Organization Studies (pp.175-190). London: SAGE.

Weick, K. (1969).

The psychology of organizing. Reading: Addison-Wesley Publ. Co.

Westphal, J., \&

Zajac, E. (2001).

Decoupling policy from practice: the case of stock repurchase programs. Administrative Science Quarterly, 46(2), 202-228.

Zucker,L. (1991).

The role of institutionalization in cultural persistence. In W. Powell \& P. DiMaggio (Eds.). The new institutionalism in organizational analysis (pp. 83-107). Chicago: The University of Chicago Press. 